\title{
A Case for Increased Medical Student and Psychiatric Resident Education in Palliative Care
}

\author{
Richard Balon ${ }^{1}$ Lucie Bankovska Motlova ${ }^{2}$ - Eugene V. Beresin ${ }^{3}$ • \\ John H. Coverdale ${ }^{4}$ - Alan K. Louie ${ }^{5}$. Laura Weiss Roberts ${ }^{5}$
}

Received: 13 November 2015 / Accepted: 8 December 2015 /Published online: 29 December 2015

(C) Academic Psychiatry 2015

Madness and death are primordial fears for us all.

Death is inevitable but madness may not be.

$$
\text { -A. D. Macleod ([1], p. 341) }
$$

With the progress of modern medicine, many previously lethal diseases now have become chronic conditions, as pointed out by Macleod [1]. During the prolonged course of illness, medical and social complications accumulate that may erode patients' quality of remaining life, including their psychological well-being ("Often the organ to suffer most is the brain" [1], p. 340). Macleod questioned the role of psychiatrists in palliative medicine, however, and recommended instead that palliative medicine trainees learn about psychiatry. In response, Strouse [2] wrote that this picture was perhaps "too fatalistic" (p. 1166) and that psychiatrists, on the basis of their experience of laboring at the interface of medicine and psychiatry (e.g., in consultation/liaison work and psycho-oncology), have much to contribute to the field of palliative care. He pointed out two new forces in favor of greater involvement of psychiatry in palliative care: the expansion of integrated care, of which palliative care is a primary example, and the evolution of the clinical role of the psychiatrist/psycho-oncologist into that of a more fully formed palliative care physician [2].

Richard Balon

rbalon@wayne.edu

\footnotetext{
Wayne State University School of Medicine, Detroit, MI, USA

Charles University, Prague, Czech Republic

Harvard Medical School, Boston, MA, USA

4 Baylor College of Medicine, Houston, TX, USA

5 Stanford University, Stanford, CA, USA
}

In 2013, only 58 psychiatrists and 41 neurologists achieved hospice and palliative medicine subspecialty certification in the USA [2]. Fairman and Irwin [3] note that despite the fact that the American Board of Psychiatry and Neurology is one of the 10 boards of the Accreditation Council for Graduate Medical Education (ACGME), only 15 psychiatrists were certified in palliative care fellowships in 2008, 12 in 2010, and 34 in 2012. Although the numbers of board-certified practitioners have been increasing, psychiatry's involvement is woefully inadequate, given the aging of the population and increasing clinical needs. The reasons for this lack of involvement are multifaceted and far from being adequately investigated.

Training psychiatrists and other specialists in palliative medicine, moreover, is not the only goal in end-of-life care. All physicians should be able to provide help to patients with terminal illness, to communicate with them and with their families comfortably, to answer their questions adequately, to be able to alleviate their suffering (physical and psychological) adequately and appropriately, and to provide palliative care. The question is whether medical students and residents receive training for palliative and end-of-life care and whether that training is adequate.

In addition, palliative care is highly misunderstood by both the general public and health care professionals. As opposed to hospice care at the end of life, which focuses on comfort measures when all medical efforts for amelioration of illness are absent, palliative care may be used at any point in serious illness, not simply at the terminal stage. Palliative care is intended to provide guidance and healing measures to improve the quality of life regardless of the state or specific course of an illness [3]. Indeed, palliative care may well be part of curative treatment, and it combines a multidisciplinary approach for multiple needs of the patient and family. Such needs include medical care, pain management, psychiatric treatment of cooccurring disorders, spiritual assistance, and help with a wide 
range of dispositions. The primary intent of palliative care is to provide support and education and to alleviate suffering.

Dickinson [4], who has surveyed US medical school offerings on end-of-life issues every 5 years between 1975 and 2010 , found that education in death and dying increased. Beginning in 2000, all schools surveyed offered some education on death and dying, and by 2010, nearly all schools offered some education on palliative care. In a national probability sample of medical trainees and faculty [5], however, US medical students and residents believed that they were unprepared to provide good care for the dying, and residents and faculty felt that they were unprepared to teach others about it. Horowitz and colleagues [6], in their review of US medical school surveys on teaching about palliative and end-of-life care, found varied and uneven approaches, ranging from $2 \mathrm{~h}$ in the classroom on end-of-life care to weeks of palliative training or hospice-based clinical rotations. They emphasized, "If palliative care competencies are of universal importance, they cannot be relegated to a minimum of classroom time and random clinical exposures" ([6], p. 63).

Education and training in palliative and end-of-life care in other countries is not better. Oneschuk and colleagues [7], in their 2000 survey, found that the highest percentage of mandatory (i.e., required by the university) rotations in palliative medicine was in UK medical schools (64\%). The numbers were considerably lower in other surveyed countries/areas: USA, $11 \%$; Canada, $14 \%$; and Western Europe, $19 \%$. Offering elective rotations in palliative medicine was a bit better (again the UK leading, with $82 \%$ ), as was providing educational reading material in palliative medicine. Very discouraging were the numbers of academic faculty positions for palliative medicine and the median number of these positions for the countries (Canada, 2 positions; the rest, 1). The UK, where the modern hospice movement originated, also did better in a study comparing the end-of-life and palliative care education of medical students in the UK and the USA [8]. As LloydWilliams and Macleod [9] pointed out, palliative care education around the world tends to be fragmented, ad hoc, and lacking coordination. Palliative care is rarely formally assessed, and its teaching is more focused on the acquisition of knowledge and skills rather than attitudes. They emphasized, "It is important that doctors realize that patients who are at the end of life, need and deserve as much of their skill and attention as those who are curable" ([9], p. 688).

Psychiatry residency training in end-of-life care and palliative medicine also is lacking. In a mixed qualitative and quantitative survey of psychiatric resident at the University of Toronto, Tait and Hodges [10] found that psychiatric residents believed they were poorly prepared to deliver end-of-life care, particularly the nonphysical aspects of caring for patients who are dying. Although the residents demonstrated capacity for reflection on experiences with dying and the impact on practice, the authors believed that trainees caring for dying patients also need more formal opportunities to debrief and learn strategies for managing their reactions. In a study by Irwin and colleagues [11], 52 psychiatry program directors and 98 psychiatry residents completed an online survey assessing the current course offering and level of interest in palliative care in the USA. Few programs offered formalized training in palliative care, although nearly all surveyed residents reported interest in this area. Winer [12] pointed out that few psychiatry residents are able to participate in palliative care fellowship programs because the medicine requirements are beyond the scope of psychiatry training. Many programs are reluctant to consider applicants who are not fully trained in medicine, making the application process for palliative care fellowships even more complicated.

The present-day education and training in end-of-life and palliative medicine are clearly unsatisfactory. Psychiatry, especially in the era of rapidly evolving integrated care and improved education in integrated care, should step up its efforts to better prepare medical students and psychiatry residents and even psychiatrists in practice to provide end-of-life and palliative care for patients. Psychiatry clearly has a role to be an integral part of the team, or at least to be regularly involved in consulting roles, given the prevalence of anxiety, mood disorders, and delirium and the complex dynamic individual and family issues in palliative care, and a substantial role for psychotherapy [3].

Few studies have demonstrated that educational interventions may help improve knowledge and comfort with end-oflife care. For example, Schillerstrom, Sanchez-Reilly, and O'Donnell [13] conducted a study of 222 first-year medical students who were divided into small discussion groups in which they discussed death and dying issues with a palliative medicine interdisciplinary member and one family member of a recently deceased hospice patient. The majority of students reported increased comfort levels and improved knowledge of end-of-life issues. Irwin and colleagues [11] surveyed 30 psychiatry residents who completed a 32-144-h required clinical rotation in hospice and palliative care and compared them with 100 family medicine and 185 internal medicine residents who completed the same clinical rotation. Self-perceived competence significantly increased from the first to the last day of the clinical rotation, as did knowledge of pain assessment, pain management, and non-pain management. Knowledge of non-pain assessment, side effects, and communication did not improve, however.

Fairman and Irwin [3] suggest that a new subspecialty field is emerging at the intersection of palliative medicine and psychiatry - palliative care psychiatry. This discipline, in their opinion, brings expertise in psychosocial dimensions of human experience to the care of dying patients and support of their families. They pointed out symptoms such as anxiety, depression, and confusion that can go underrecognized and underappreciated in palliative care, about which psychiatrists 
can provide expertise, as well as on new psychotherapies for possible implementation, such as Meaning-Centered Psychotherapy and Dignity Therapy. Interestingly, as they pointed out, no clinical trials focused on delirium in the palliative care setting have been conducted. Irwin and Ferris [14] suggested that integrating psychiatrists into interdisciplinary palliative care teams will lead to better results for patients and their families. Horowitz and colleagues [6] proposed that basic palliative care competencies should be defined and integrated into each year of the medical school. Winer [12] noted that whereas psychiatry residents are more removed from death and dying than residents of other specialties, at the end of training, they are expected to address issues involving patients nearing the end of life. She also noted that psychiatry departments rarely have formal connections with palliative care programs at their institutions.

These are important statements and calls for action. No official standards and requirements for end-of-life and palliative care are well established in the USA and elsewhere, however. As pointed out by Horowitz and colleagues [6], the Liaison Committee on Medical Education (LCME) does not require US medical schools to teach palliative care, and the word palliative is not even mentioned in its standards [15]. The LCME standards only suggest that schools include "important aspects" of end-of-life care. The ACGME Residency Committee for Psychiatry does not mention palliative care in its requirements. The geriatric psychiatry fellowship requirements specify that the geriatric care team should possibly include hospice and a palliative care specialist, who should be available for consultation. The psychosomatic medicine fellowship requires that fellows must demonstrate proficiency in evaluating and managing individuals with palliative care and end-of-life issues. These requirements are not enough; they include teaching only a small portion of practicing psychiatrists and do not address the lack of training in palliative care during general psychiatric residency training.

The European Association for Palliative Care (EAPC) developed general recommendations for curriculum development in palliative care and a white paper on palliative care education [16]. They defined palliative care as "the active, total care of the patients whose disease is not responsive to curative treatment" ([16], p. 7) and proposed that it be introduced as a mandatory subject within the medical curricula of all European medical schools. They recommended a 40-h curriculum, which would address six areas: basics of palliative care, pain and symptom management, psychosocial and spiritual aspects, ethical and legal issues, communication, and teamwork and self-reflection. This proposed curriculum is based on what they believe is the minimal knowledge and skills that medical students should obtain during their undergraduate education. Control of pain or other symptoms and social, psychological, and spiritual problems is paramount. Palliative care is interdisciplinary in its approach and encompasses the patient, the family, and the community in its scope. In a sense, palliative care is to offer the most basic concept of care - providing for the needs of the patient wherever he or she is cared for, whether at home or in the hospital, for example. As the EAPC states, "Palliative care affirms life and regards dying as a normal process; it neither hastens nor postpones death. It sets out to preserve the best possible quality of life until death" ([15], p. 7). These recommendations are definitely a worthy consideration by the LCME and other national or multinational accrediting bodies for introduction into medical school curricula.

Psychiatry as a discipline should also develop a curriculum in palliative and end-of-life care. Residency training programs should be encouraged and perhaps mandated to introduce rotations in palliative care (including hospice visits). Much of this training and education could readily be included in consultation/liaison and geriatric psychiatry clinical rotations. Recommendations for teaching could use some of those proposed by Lloyd-Williams and MacLeod [9] for medical students - ensuring that actual knowledge and essential core information is taught, using small groups for problem-based learning and multidisciplinary teaching. This teaching could include all team members along with their patients and family in the teaching, integrate teaching and combine disciplines and principles, foster reflective learning (considered a very important part of learning in this area [17]), include ethical and legal issues of relevance to end-of-life care, and ensure that trainees have effective mechanisms to deal with the professional and personal pressures of this aspect of work [9].

It is time for a profound and substantial change in psychiatry's attitude toward palliative care. It is time to move from a seemingly "benign neglect" to a much more active role for psychiatry in palliative and end-of-life care. In many aspects, psychiatry itself is a form of palliative care because psychiatric treatments are frequently not curative. Psychiatrists have much to contribute to an improvement in palliative care. A recent example is the possible use of ketamine for depression in patients receiving hospice care [18]. And, as Irwin and Ferris [14] wrote, "Will your health care system be competent to maintain your comfort and meet your needs, ensuring that you and your family face death with as much comfort, peace of mind, and dignity as possible? Psychiatrists are well poised to ensure that the answer to this provocative question is yes" ([14], emphasis added).

\section{References}

1. Macleod AD. Palliative medicine and psychiatry. J Palliat Med. 2013;16:340-1.

2. Strouse T. Palliative medicine and psychiatry: a reply. J Palliat Med. 2013;16:1166-7. 
3. Fairman N, Irwin SA. Palliative care psychiatry: update on an emerging dimension of psychiatric practice. Curr Psychiatr Rep. 2013; $15: 374$.

4. Dickinson GE. Thirty-five years of end-of-life issues in US medical schools. Am J Hosp Palliat Care. 2011;28:412-7.

5. Sullivan AM, Lakoma MD, Block SD. The status of medical education in end-of-life care; a national report. J Gen Intern Med. 2003;18:685-95.

6. Horowitz R, Gramling R, Quill T. Palliative care education in U.S. medical schools. Med Educ. 2014;48:59-66.

7. Oneschuk D, Hanson J, Bruera E. An international survey of undergraduate medical education in palliative medicine. J Pain Symptom Manag. 2000;20:174-9.

8. Hammel JF, Sullivan AM, Block SD, Twycross R. End-of-life and palliative care education for final-year medical students: a comparison of Britain and the United States. J Palliat Med. 2007;10:1356-66.

9. Lloyd-Williams M, MacLeod RD. A systematic review of teaching and learning in palliative care within the medical undergraduate curriculum. Med Teach. 2004;26:683-90.

10. Tait GR, Hodges BD. End-of-life care education for psychiatric residents: attitudes, preparedness, and conceptualizations of dignity. Acad Psychiatry. 2009;33:451-6.

11. Irwin SA, Montross LP, Bhat RG, Nelesen RA, von Gunten CF. Psychiatry resident education in palliative care: opportunities, desired training, and outcomes of a targeted educational intervention. Psychosomatics. 2011;52:530-6.

12. Winer RA. Formalizing palliative training in psychiatry residency programs. Acad Psychiatry. 2013;37:444-6.

13. Schillerstrom JE, Sanchez-Reilly S, O’Donnell L. Improving student comfort with death and dying discussions through facilitated family encounters. Acad Psychiatry. 2012;36:188-90.

14. Irwin SA, Ferris FD. The opportunity for psychiatry in palliative care. Can J Psychiatry. 2008;53:713-24.

15. Liaison committee on medical education. Standards. Available at http://www.lcme.org/functions.pdf. Accessed 4 Oct 2015.

16. European association for palliative care. Recommendations of the European Association for Palliative Care (EAPC) for the development of undergraduate curricula in palliative medicine at European medical schools. Milano, Italia, EAPC, 2013. Available at www. eapcnet.eu/LinkClick.aspx?fileticket=S1MI-tuIutQ\%3D. Accessed 12 Nov 2015.

17. MacLeod RD, Parkin C, Pullon S, Robertson G. Early clinical exposure to people who are dying: learning to care at the end of life. Med Educ. 2003;37:51-8.

18. Iglewicz A, Morrison K, Nelesen RA, et al. Ketamine for the treatment of depression in patients receiving hospice care: a retrospective medical record review of thirty-one cases. Psychosomatics. 2015;56:329-37. 